\title{
Dinheiro e sucesso eleitoral em 2008, 2012 e 2016 no Brasil
}

\author{
Jacques Paul Deschamps ${ }^{1}$ \\ Ivan Jairo Junckes ${ }^{2}$ \\ Rodrigo Rossi Horochovski ${ }^{3}$ \\ Neilor Fermino Camargo 4 \\ 1 Universidade Federal do Paraná / Setor Litoral, Matinhos / PR - Brasil \\ 2 Universidade Federal do Paraná / Programa de Pós-Graduação em Desenvolvimento Territorial Sustentável, Matinhos / PR - Brasil \\ 3 Universidade Federal do Paraná / Programa de Pós-Graduação em Ciência Política, Curitiba / PR - Brasil \\ ${ }^{4}$ Universidade Federal do Paraná / Curso de Administração Pública, Matinhos / PR - Brasil
}

\begin{abstract}
A intimidade entre dinheiro e voto tem sido exposta nas democracias contemporâneas por meio de sua influência nos resultados eleitorais e na produção de políticas públicas. Estudos apontam que a progressiva iniquidade entre os recursos financeiros dos candidatos nas eleições abala a democracia e promove a plutocracia, ou seja, amplia o domínio oligárquico dos processos políticos pelos cidadãos e pelos grupos mais ricos. Contribuindo para esse debate, o presente trabalho analisa a relação entre receitas de financiamento e o desempenho e o sucesso eleitoral de 317.107 candidaturas a vereador nas eleições de 2008, 2012 e 2016, em 441 municípios brasileiros com mais de 50 mil eleitores. Trata-se de um estudo inédito em sua abrangência temporal, que permite suprir uma carência de exames sobre eleições subnacionais, em especial nas disputas ao Legislativo municipal. Os dados utilizados têm origem no Tribunal Superior Eleitoral, nas tabelas de candidaturas, nos resultados e na prestação de contas. Os testes e as análises de dados e informações utilizam recursos estatísticos de correlação e regressão, além de medidas centrais e razão de chances. Os resultados permitem confirmar uma forte associação entre dinheiro, voto e sucesso eleitoral, inclusive no pleito de 2016, quando estiveram proibidas as doações empresariais. A manutenção de um padrão, tanto temporal quanto geográfico, indica a existência de características estruturais de caráter plutocrático no financiamento eleitoral dos candidatos a vereador nas cidades pesquisadas e, consequentemente, sobre a produção de políticas públicas no Brasil.
\end{abstract}

Palavras-chave: financiamento eleitoral; eleição municipal; democracia; plutocracia; vereadores.

\section{Dinero y éxito electoral en 2008; 2012 y 2016 en Brasil}

La intimidad entre dinero y voto ha sido expuesta en las democracias contemporáneas a través de su influencia en los resultados electorales y en la producción de políticas públicas. Los estudios muestran que la desigualdad progresiva entre los recursos financieros de los candidatos en las elecciones debilita la democracia y promueve la plutocracia, es decir, aumenta el dominio oligárquico en los procesos políticos por parte de los ciudadanos y grupos más ricos. Contribuyendo a este debate, el presente trabajo analiza la relación entre los ingresos por financiamiento y el desempeño y el éxito electoral de 317.107 candidatos a concejal en las elecciones de 2008, 2012 y 2016 en 441 municipios brasileños con más de 50 mil votantes. Es un estudio sin precedentes en su alcance temporal que permite suplir la falta de estudios sobre elecciones subnacionales, especialmente en disputas relacionadas con el Poder Legislativo Municipal. Los datos utilizados provienen del Tribunal Superior Electoral, de los cuadros de candidaturas, resultados y rendición de cuentas. Las pruebas y análisis de datos e información utilizan recursos estadísticos de correlación y regresión, además de medidas centrales y razón de probabilidades. Los resultados confirman una fuerte asociación entre dinero, votación y éxito electoral, incluso en las elecciones de 2016, cuando se prohibieron las donaciones corporativas. El mantenimiento de un patrón tanto temporal como geográfico indica la existencia de características estructurales de carácter plutocrático en el financiamiento electoral de los candidatos a concejal en las ciudades encuestadas y, en consecuencia, en la producción de políticas públicas en Brasil.

Palabras clave: financiamiento electoral; elección municipal; democracia; plutocracia; concejales. 


\section{Money and success in the 2008, 2012, and 2016 local elections in Brazil}

The close relationship between money and votes has been exposed in contemporary democracies through the influence of the former in election results and in the creation of public policies. Studies have pointed out that the progressive inequity of financial resources available to the candidates running for elections unbalances democracy and promotes plutocracy, increasing the oligarchical ruling over the political processes by the wealthiest citizens and groups. This work contributes to this debate by analyzing the relationship between fundraising and electoral performance and the success of 317,107 candidates running in local legislative elections in 2008, 2012, and 2016 in 441 Brazilian municipalities with over 50,000 inhabitants. This is an unprecedented study regarding its period, filling a gap in electoral studies on sub-national elections, particularly regarding elections for the legislative branch. Data was collected from the Brazilian Superior Electoral Court, from candidate lists, results, and accounting. The tests and data analysis and information employed correlation and regression statistical resources, along with central measures and odds ratio. The results confirmed a strong association between money, vote, and electoral success, including in the 2016 election when company donations had been prohibited. The maintenance of a pattern, regarding both time and geography, indicates the existence of structural characteristics of a plutocratic character in the election funding of those running for the council in the municipalities studied and, consequently, in the creation of public policies in Brazil.

Keywords: election funding; municipal election; democracy; plutocracy; city councilors.

\section{AGRADECIMENTOS}

Registramos nosso reconhecimento ao Conselho Nacional de Desenvolvimento Científico e Tecnológico (CNPq), que apoiou a pesquisa por meio de financiamento ao Projeto 8629 - Impactos da proibição do financiamento empresarial nas eleições de 2016 no Brasil. Agradecemos, também, aos pareceristas anônimos pelas valiosas contribuições que possibilitaram significativas melhorias ao artigo.

\section{INTRODUÇÃO}

Visando contribuir para as discussões sobre limites e desafios do financiamento da democracia no Brasil, este artigo analisa a influência das relações plutocráticas sobre as eleições. São investigados 317.107 candidatos a vereador nos pleitos de 2008, 2012 e 2016, em 441 municípios com mais de 50 mil eleitores. A análise longitudinal realizada aqui diferencia este trabalho da maioria da literatura brasileira que estuda o papel do dinheiro nas eleições municipais (Sampaio \& Figueiredo, 2019). O estudo se reveste de importância por explorar, em ampla escala, o cargo que se constituiu historicamente como a porta de entrada de legisladores e administradores na vida pública.

Esforços normativos têm sido realizados para reduzir ou limitar a influência do dinheiro nas eleições - alguns bem-sucedidos; outros, inócuos ou reversos. Entre 1993 e 2014, durante a vigência da Lei 8.713/1993 (e suas atualizações), foram permitidas doações de pessoas jurídicas destinadas para candidatos, partidos políticos e comitês eleitorais. Nas eleições de 2014, foram mobilizados cerca de 4,2 bilhões de reais em doações declaradas à Justiça eleitoral, sendo pouco mais de 3 bilhões de origem empresarial. As eleições dos anos anteriores - nacionais, estaduais ou municipais - apresentaram cifras igualmente bilionárias de investimentos corporativos.

A Lei 13.165/2015 proibiu as doações empresariais de campanhas nas eleições subsequentes, com o objetivo de reduzir o peso dos recursos financeiros no processo eleitoral. Essa alteração teve origem 
na Ação Direta de Inconstitucionalidade (ADI) 4.650/11, proposta pela Ordem dos Advogados do Brasil (OAB) ao Supremo Tribunal Federal (STF), em setembro de 2011.

$\mathrm{Na}$ ação, a $\mathrm{OAB}$ alegou que o sucesso eleitoral depende de campanhas com custos financeiros elevados, tornando a política demasiado dependente do poder econômico. Tal dinâmica seria prejudicial ao funcionamento da democracia, gerando graves distorções. Em primeiro lugar, porque promove uma desigualdade política, ao aumentar a influência dos mais ricos sobre os resultados eleitorais e, por conseguinte, sobre a ação do poder público. Em segundo, porque diminui as chances de candidatos sem recursos financeiros expressivos nem proximidade com detentores do poder econômico. Em terceiro, porque cria vinculações nefastas entre financiadores e políticos, que acabam se tornando fontes de favorecimento após os pleitos (Supremo Tribunal Federal, 2011). Em 2015, na sessão do STF que deliberou pela proibição das doações empresariais, o ministro Luiz Fux declarou que "chegamos a um quadro absolutamente caótico em que o poder econômico captura, de maneira ilícita, o poder político" (Supremo Tribunal Federal, 2016, p. 276).

O primeiro campo de testes dos efeitos da Lei 13.165/2015 foi o pleito municipal de 2016, numa oportunidade ímpar de estudo. A expectativa midiática era que as novas regras limitassem a ação do dinheiro sobre o desempenho e o sucesso eleitoral no Brasil, promovendo maior equidade entre os competidores. Será que isso de fato ocorreu? Em busca de uma resposta, orientamos a pesquisa pelas seguintes questões: em 2016, maiores receitas financeiras de campanha resultaram na obtenção de mais votos, ou seja, em melhor desempenho eleitoral? Elas aumentaram as chances de sucesso eleitoral, isto é, de os candidatos se elegerem?

A hipótese que testamos aqui é a de que a eleição de 2016, sob vigência da proibição do financiamento empresarial, manteve o padrão das eleições de 2008 e 2012 de forte relação entre recursos financeiros, desempenho e sucesso eleitoral dos candidatos a vereador nos municípios pesquisados.

O artigo está dividido em 4 partes, além desta Introdução. A primeira constitui uma breve discussão do problema de pesquisa, com uma contextualização teórica sobre o financiamento eleitoral e seus impactos e desdobramentos sobre as eleições e a democracia brasileira. A seguir, são descritos materiais e métodos, ou seja, os procedimentos de coleta e organização dos dados, os municípios que compõem o objeto da pesquisa e as ferramentas, sobretudo estatísticas, empregadas nas análises.

Na seção empírica, apresentamos e discutimos os principais achados do trabalho, primeiramente, mediante testes de correlação e regressão linear, a fim de verificar a relação entre receita e desempenho eleitoral das candidaturas ao cargo de vereador investigadas; na sequência, com cálculos de receita média e distribuição dos candidatos por quartis de arrecadação financeira, além de testes de razão de chances, para estabelecer a relação entre receitas e sucesso eleitoral. Nas considerações finais, sintetizamos os principais resultados e apontamos perspectivas de ampliação das pesquisas relativas à dinâmica plutocrática e suas implicações para o regime democrático brasileiro.

\section{PLUTODEMOCRACIA: DINHEIRO, VOTO E PODER PÚBLICO}

O voto é requisito da democracia, pois eleições permitem aos cidadãos avaliar os governantes, mantendo ou mudando os agentes políticos responsáveis por coordenar processos decisórios e implantar políticas públicas. Um dos efeitos da universalização do sufrágio tem sido o aumento do custo da competição política e a exigência de recursos financeiros consideráveis para sustentar as formas de propaganda impostas pela midiatização eleitoral. 
A capacidade de arrecadação assumiu um papel preponderante no processo eleitoral, a ponto de, para a maioria dos candidatos que arrecada pouco ou quase nada, se tornar inviável executar atividades centrais de campanha, como se relacionar virtualmente com a massa de eleitores. Sem recursos, reduzem-se drasticamente as chances de êxito eleitoral.

$\mathrm{O}$ volume de recursos arrecadados tem sido um fator altamente preditivo sobre os resultados das eleições, fazendo do poder econômico um elemento essencial para que um desafiante seja bem-sucedido ou para que um incumbente possa se manter na arena política (Cervi, 2010; Dias, Nossa \& Monte-Mor, 2018; Figueiredo, 2009; Heiler, 2011; Junckes, Horochovski, Camargo, Silva \& Chimin, 2019; Lemos, Marcelino \& Pederiva, 2010; Mancuso \& Speck, 2015; Peixoto, 2010; Reis \& Eduardo, 2019; Sacchet \& Speck, 2012a, 2012b).

O alto comprometimento de algumas empresas na política criou a imagem de que doações resultam em favores e contribuiu para que se enxergasse a democracia brasileira como uma plutocracia (Speck, 2016). Esse conceito é um desenvolvimento ulterior da análise do papel político das oligarquias, pelo qual o dinheiro se impõe, mesmo em regimes formalmente democráticos. Bianchi e Aliaga (2011), além de Couto (2012), mostram que o resgate e a problematização desse termo de origem grega foram, modernamente, trazidos pelo chamado elitismo clássico do início do século XX, cujos expoentes principais são Michels (1982), Mosca (1939) e Pareto (1966). Para eles, a proeminência do dinheiro inviabilizaria as próprias promessas da democracia, mantendo-a como um regime de dominação de elites, numa plutodemocracia (Finer, 1968).

A adoção acrítica de uma visão como a elitista acarreta riscos de jogar a democracia na vala comum dos demais regimes, negando a melhoria do sistema político no sentido de uma participação ampliada e menos assimétrica do conjunto dos cidadãos. Entretanto, nos últimos anos, diversos autores têm apontado limites da democracia liberal representativa, asseverando que ela passa por dificuldades relacionadas ao recrudescimento das desigualdades e do autoritarismo em escala planetária (Levitsky \& Ziblatt, 2018; Miguel, 2014). Para Milanovic (2016), trata-se da emergência de uma plutocracia global, fenômeno que converge com o crescimento do populismo no início do século XXI, repondo a noção de plutocracia demagógica como destino da democracia liberal (Pareto, 1966).

Dada a necessidade de definir os termos do debate, para os propósitos deste trabalho, plutocracia é o sistema político no qual a posse de riqueza econômica está relacionada à efetivação de preferências e interesses por meio da conquista de posições e influência na estrutura do Estado, nos processos decisórios e na produção de políticas públicas. Alternando ou combinando democracia e plutocracia, candidatos com programas mais próximos aos dos grandes interesses econômicos teriam mais chances de se eleger do que outros. Em outros termos, "a representação seria plutocrática, e não da pólis" (Speck, 2005, p. 141).

Sem considerar que o dinheiro em si possa ser "a raiz de todo mal", tal qual alerta Scarrow (2007), a questão que se coloca é quando e quanto o dinheiro se torna um problema ao influenciar, ou mesmo determinar, os resultados das eleições e a governança pública.

Dawood (2015) afirma haver pouco consenso em questões como representação democrática, corrupção, influência política e governança. Embora a demonstração empírica da "venda" de influência política tenha sido realizada com limitações na literatura estadunidense, há evidências que associam o fluxo de dinheiro doado legalmente à produção de políticas públicas. Conclusões e limitações semelhantes são relatadas por Santos (2016) em sua tese de doutorado sobre as relações entre financiamento eleitoral e produção legislativa no Brasil, com resultados publicados em Dinheiro, eleições e poder (Carazza, 2018). 
Em seus estudos, Santos (2016) respalda a hipótese de que doações empresariais afetam resultados eleitorais e são motivadas por expectativas de favorecimento durante os mandatos. Para tanto, aponta o aumento dos recursos envolvidos nas campanhas, a dominância das milionárias doações empresariais sobre a ínfima parcela do eleitorado que realiza alguma contribuição, a expressiva participação dos recursos de autofinanciamento, o protagonismo crescente dos partidos políticos e a concentração de recursos empresariais em candidaturas com mais chances de vitória. O autor conclui que a especialização da produção legislativa entre os poderes Executivo e Legislativo gera oportunidades para a atuação dos grupos de interesse em atividades de rent seeking.

Santos, Silva, Figueiredo e Rocha (2015) demonstram que o posicionamento dos deputados federais brasileiros entre 1999 e 2007 no Congresso tendeu a ser controlado pela proporção de recursos corporativos que receberam quando candidatos, pelo menos em relação aos interesses legislativos da Confederação Nacional da Indústria (CNI). Uma análise da legislatura 2011-2014 encontrou forte relação positiva entre o volume de doações da indústria e a quantidade de proposições convergentes para os interesses do setor (Mancuso, Santos, Resende \& Barboza, 2020). As relações entre financiamento eleitoral e produção legislativa passam também pela assimétrica presença dos parlamentares mais bem financiados nas comissões de maior correspondência aos interesses dos setores econômicos e de grandes grupos financiadores (Geara, Junckes, Horochovski \& Clemente, 2018; Horochovski, Junckes \& Serafim, 2020).

Citando uma série de fatores de influência exercidos pelos eleitos e utilizando análises de regressão descontínua, Araújo (2012) infere que os financiadores dos deputados federais eleitos em 2006 ampliaram a quantidade de contratos públicos entre 2008 e 2010, em comparação com os financiadores dos não eleitos. Utilizando a mesma metodologia e analisando dados de contratos entre 2004 e 2010, Boas, Hidalgo e Richardson (2014) constatam que empresas operadoras de projetos de obras públicas poderiam obter um incremento em seus contratos de até 14 vezes o valor das contribuições efetuadas para um candidato do partido no Executivo. Conclusão semelhante apontam Arvate, Barbosa e Fuzitani (2013) ao investigarem a dinâmica das eleições estaduais. As doações de uma empresa visam influenciar sua relação de contratação com o setor público e de outras a ela relacionadas, portanto a inter-relação entre os atores corporativos pode explicar mais sobre suas estratégias de influência do que a análise de suas ações em particular (Chagas, Haddad \& Chagas, 2015).

As doações, ou investimentos eleitorais (Mancuso, 2015), são afetadas principalmente por determinantes políticos - capital político, porte e ideologia partidária, entre outros - e também por características individuais dos candidatos - gênero, escolaridade e ocupação. Para Silva e Cervi (2017), as doações de campanha são distribuídas de maneira desigual entre os candidatos, beneficiando determinado perfil político e social. Assim, um dos impactos mais observados do dinheiro sobre a disputa eleitoral é o desequilíbrio que ele causa, pois candidatos com mais recursos têm mais chances de vencer.

Nas eleições para deputado federal em 2014, empresas e dirigentes partidários apresentaram uma tendência à manutenção do status quo, direcionando os recursos financeiros de forma a garantir a manutenção de mandatos. A partilha das doações empresariais, realizadas direta ou indiretamente (via partidos), não favoreceu valores democráticos importantes; pelo contrário, colaborou para a manutenção de uma elite política vinculada a estruturas sociais tradicionalmente privilegiadas (Mancuso, Horochovski \& Camargo, 2018). Ou seja, mantêm-se no Brasil o que Weber denominou de "recrutamento plutocrático" da classe política (Codato, 2014), sendo o financiamento eleitoral um dos principais fatores explicativos para a manutenção dessa lógica (Cervi, Costa, Codato \& Perissinotto, 2015). 
Os estudos sobre os determinantes do investimento e sua relação com os resultados eleitorais têm sido favorecidos pela ampla acessibilidade aos dados eleitorais de candidaturas e prestação de contas formais em repositórios públicos, em especial aqueles disponibilizados pelo Tribunal Superior Eleitoral (TSE). Para quase todos, vale a questão apontada por Samuels (2001) sobre qual é a fonte dos recursos e quão acentuada é sua concentração para medir os impactos do dinheiro sobre a democracia competitiva no Brasil.

Organizando grandes bancos de dados e utilizando desde recursos estatísticos simples até complexos testes e métricas de rede, os estudos em geral constatam que incumbência, magnitude do distrito, porte partidário, sexo, cor, escolaridade e pertencimento à base governamental são variáveis que influenciam de forma significativa as receitas de um candidato. Como resultado, há uma forte associação entre arrecadação, desempenho e sucesso eleitoral.

Mancuso e Speck (2014) descrevem que as três fontes de recursos mais relevantes, em ordem decrescente, são as doações empresariais, as doações de pessoas físicas e os recursos próprios dos candidatos. Eles também defendem que, quando se soma o financiamento direto aos candidatos e aquele via partidos (indireto) realizado pelo setor privado, as disputas para senador, governador e presidente são financiadas quase integralmente por doações empresariais. Analisando as campanhas de 2010 e 2014 para a Câmara dos Deputados, Silva e Cervi (2017) mostram que postulantes eleitos e reeleitos são os que recebem os maiores percentuais de doações de pessoas jurídicas.

Nas eleições de 2010, as receitas eleitorais chegaram a quase 3 bilhões de reais. Cerca de $75 \%$ desse valor se referem a doações de 19 mil empresas privadas, sendo que, do montante investido por pessoas jurídicas, 50\% foram realizados por somente 70 empresas ou grupos. Nas eleições de 2014, foram arrecadados cerca de 4,2 bilhões de reais, sendo 73\%, ou pouco mais de 3 bilhões de reais, oriundos de empresas (Mancuso et al., 2018).

Horochovski, Junckes, Silva, Silva e Camargo (2016) evidenciam uma estrutura de poder por meio dos relacionamentos entre doadores e receptores nas eleições de 2010. Os autores identificam que as maiores chances para os candidatos alcançarem êxito, bem como a assertividade dos doadores em distribuir seus recursos a candidaturas vencedoras, se relacionam à ocupação de posições centrais e estratégicas na rede de financiamento de campanha. A maior ou menor centralidade de uma candidatura na rede de financiamento implica uma diferença de até 147 vezes nas chances de sucesso.

Junckes et al. (2019) demonstram que somente 5,6\% das pessoas físicas e 21,9\% das pessoas jurídicas influenciaram decisivamente a eleição da quase totalidade dos candidatos em 2014. Candidatos e financiadores que estabelecem apenas um relacionamento na rede, em especial as pessoas físicas, são "figurantes". Os autores identificaram um núcleo composto por $0,16 \%$ dos doadores (239 empresas) que financiaram $81 \%$ dos eleitos. Entre os candidatos alcançados por esses superdoadores corporativos estão 26 dos 27 senadores eleitos, 464 dos 513 deputados federais, 25 dos 27 governadores e $79 \%$ dos deputados estaduais e distritais, além da presidente. É uma rede altamente conectada, composta pelos principais grupos empresariais financiando agentes partidários e candidatos.

Diante dos impactos para a democracia e sua influência sobre as políticas públicas, o estudo do financiamento eleitoral se tornou um dos maiores desafios para pesquisadores da política brasileira. Embora haja um crescimento da literatura sobre o tema, a maioria dos estudos focaliza eleições gerais. Poucos analisam eleições municipais (Sampaio \& Figueiredo, 2019). Esta investigação supre parcialmente essa carência, apresentando uma contribuição para os debates sobre as dimensões plutocráticas do financiamento eleitoral. A próxima seção descreve como isso foi feito. 


\section{MATERIAIS E MÉTODOS}

Os dados das eleições municipais de 2008, 2012 e 2016 foram obtidos no Grupo de Estudos Territoriais (Gete) da Universidade Estadual de Ponta Grossa (UEPG) e depurados, tabulados e organizados em planilhas eletrônicas. Um arquivo CSV (codific. 1252) com os dados utilizados para o estudo está disponível em https://tinyurl.com/rtco7ed e pode ser baixado para consulta ou reteste. Os municípios brasileiros com mais de 50 mil eleitores em 2016 compõem nosso recorte, conforme indicações de Speck e Cervi (2016), assim como de Sampaio e Figueiredo (2019). Para a lista de municípios, consultar http://www.tse.jus.br/eleicoes/estatisticas/estatisticas-eleitorais. A Figura 1 mostra a distribuição dos 441 municípios abrangidos pela pesquisa.

\section{FIGURA 1 LOCALIZAÇÃO GEOGRÁFICA DOS MUNICÍPIOS COM MAIS DE 50 MIL ELEITORES}

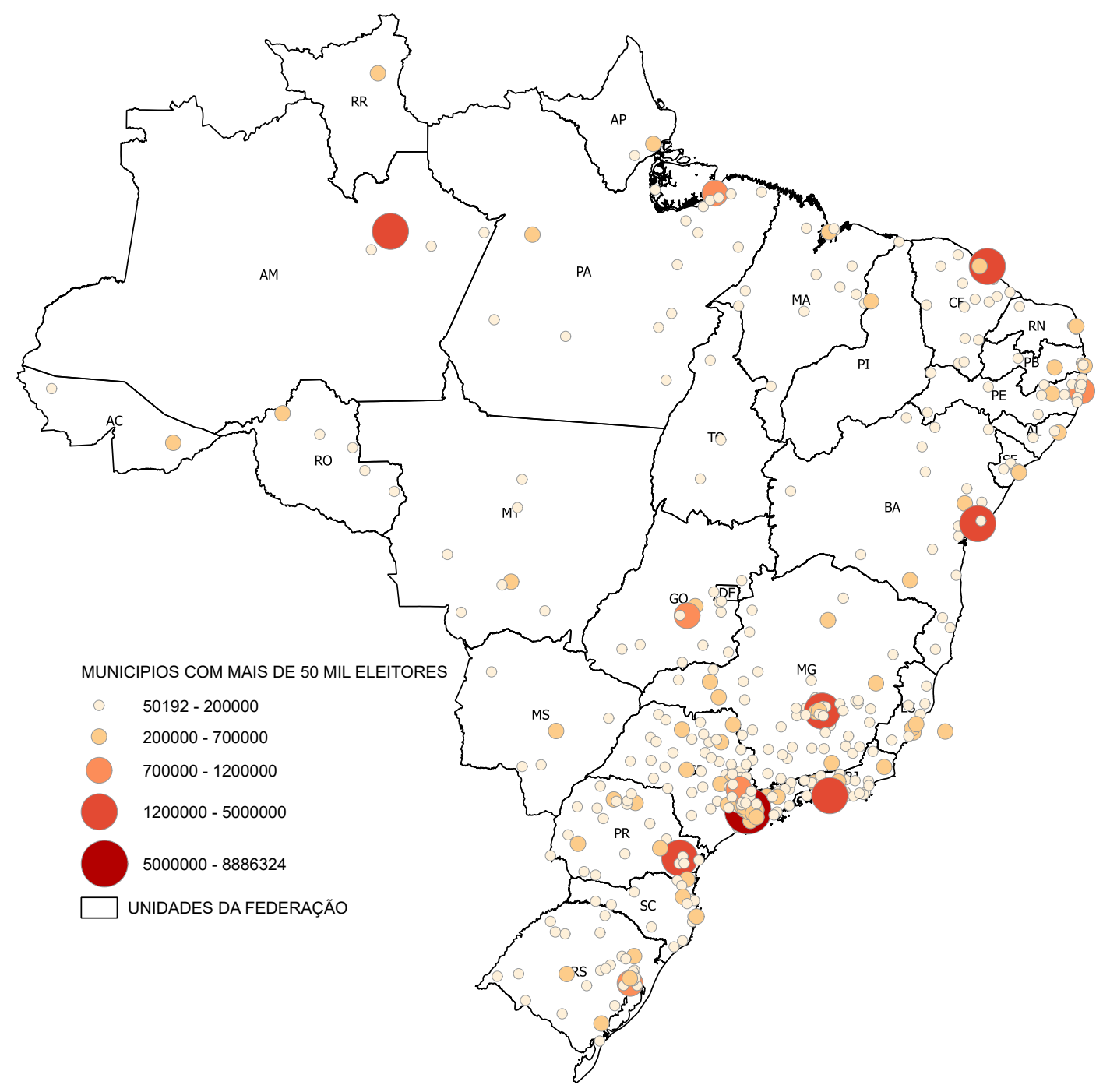

Fonte: Elaborada por Silva (Gete/UEPG). 
Em 2016, esses municípios concentravam 61\% (123.927.389) da população residente estimada no país, de acordo com https://sidra.ibge.gov.br/pesquisa/estimapop/tabelas, e 59,3\% (85.387.248) dos eleitores. Representavam, nas eleições de 2008, 2012 e 2016, respectivamente, 58\%, 57\% e 50\% do total de receitas de campanha, e $24 \%, 28 \%$ e $29 \%$ do total de candidatos ao cargo de vereador. A Tabela 1 apresenta a distribuição das 317.107 candidaturas aptas e os $\mathrm{R} \$ 2.866 .057 .116$ de financiamento eleitoral, nas três eleições, com valores atualizados pelo Índice de Preços ao Consumidor Amplo (IPCA), disponibilizados pelo Instituto Brasileiro de Geografia e Estatística (IBGE), para outubro de 2016.

\section{TABELA 1 CANDIDATURAS A VEREADOR APTAS E RECEITAS DE CAMPANHA (MUNICÍPIOS COM MAIS DE 50 MIL ELEITORES, POR ELEIÇÃO)}

\begin{tabular}{|c|cc|}
\hline Ano & Candidaturas & Receitas de campanha \\
\hline 2008 & N & R\$ \\
2012 & 79.420 & 871.500 .638 \\
2016 & 113.488 & 1.280 .946 .380 \\
\hline
\end{tabular}

Fonte: Elaborada pelos autores com base em dados do Gete, da UEPG.

Como já dissemos, a hipótese que testamos aqui é a de que a eleição de 2016, sob vigência da proibição do financiamento empresarial, manteve o padrão das eleições de 2008 e 2012 de forte relação entre recursos financeiros, desempenho e sucesso eleitoral dos candidatos a vereador nos municípios pesquisados.

Nossa variável preditora é, portanto, o total de doações recebidas e declaradas na campanha, assim como as variáveis dependentes são o desempenho dos candidatos, medido pelo total de votos obtidos, e o sucesso eleitoral, medido pela situação binária eleito vs. não eleito. A metodologia é quantitativa com análise estatística, mediante testes de correlação e regressão linear, entre receitas de campanha e votos, comparações entre receitas médias de candidatos eleitos e não eleitos, distribuição desses candidatos por quartis de arrecadação financeira e razão de chances de sucesso eleitoral. Os cálculos e os testes foram realizados no software Jamovi R.

Em 2016, o número de eleitores variou de 50.192 a 8.886.324, e os valores por município, de $\mathrm{R} \$ 149.280$ a R \$ 42.996.783. Como trabalhamos com distritos com tal variação, normalizamos os dados estabelecendo índices relativos de "participação do candidato no total de receitas dos candidatos no distrito/município" (PCRM) e de "participação do candidato no total de votos no distrito/município" (PCVM). Para a obtenção desses dados, aplicamos as seguintes fórmulas:

$$
P C R M=\frac{T R C}{T R C M}
$$


Nela, PCRM é a participação do candidato no total de receitas dos candidatos no distrito/ município, TRC é o total de receitas do candidato e TRCM é o total de receitas dos candidatos no distrito/município.

$$
P C V M=\frac{T V C}{T V M}
$$

Nela, PCVM é a participação do candidato no total de votos no distrito/município, TVC é o total de votos do candidato e TVM é o total de votos no distrito/município.

$\mathrm{Na}$ próxima seção, apresentamos e discutimos os resultados da aplicação desses procedimentos metodológicos.

\section{APRESENTAÇÃO E DISCUSSÃO DOS RESULTADOS}

\subsection{A Relação entre Receita e Desempenho Eleitoral}

Para responder à questão "maior receita financeira de campanha resulta na obtenção de mais votos?", correlacionamos receitas declaradas pelos candidatos e seus votos, utilizando tanto os dados absolutos de receitas e votos dos 317.107 candidatos quanto os dados relativos de PCRM e PCVM.

\subsubsection{Dados absolutos}

Os Gráficos 1, 2 e $3^{1}$ são diagramas de dispersão que mostram a forma e a direção do relacionamento entre as variáveis votos (dependente) e receitas (explicativa) nas eleições de 2008, 2012 e 2016.

\section{GRÁFICO 1 DIAGRAMA DE DISPERSÃO ENTRE RECEITAS DE CAMPANHA E VOTOS NAS ELEIÇÕES DE 2008}

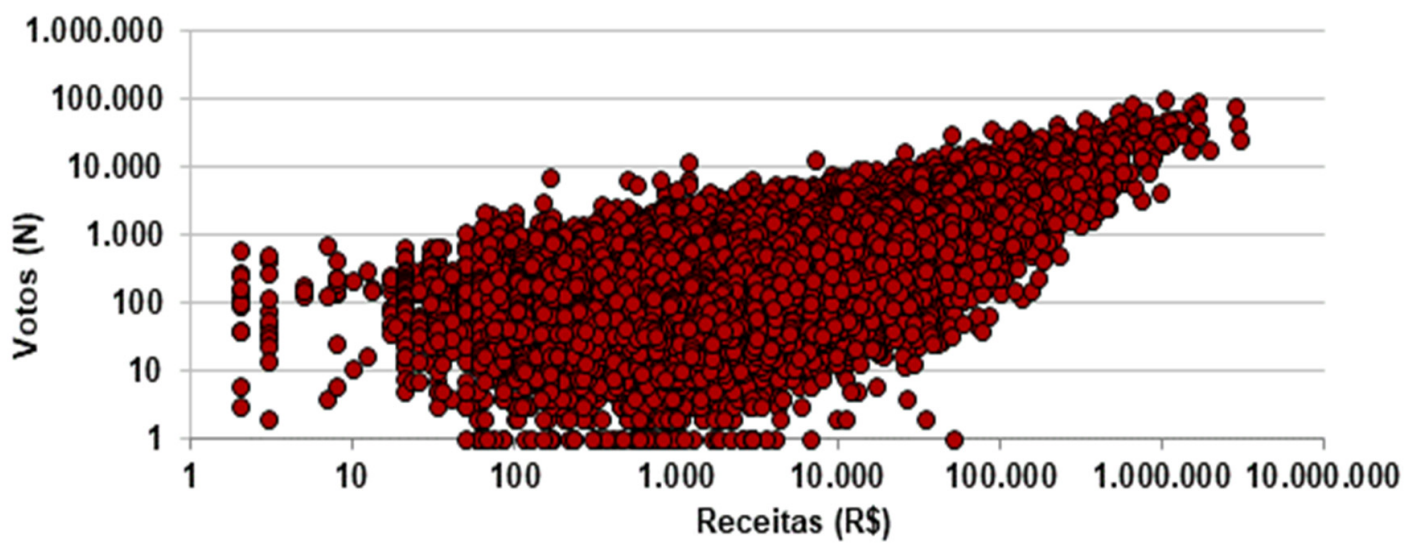

Fonte: Elaborado pelos autores com base em dados do Gete, da UEPG.

\footnotetext{
${ }^{1}$ Para melhor visualização, os gráficos se apresentam, em ambos os eixos (x e y), em escala logarítmica de base 10. Como a escala começa em 1 (um), valores iguais a 0 (zero), seja de receitas, seja de votos, apenas não estão plotados. Essa questão, porém, não interfere na nossa intenção de verificar a forma e a direção do relacionamento entre as variáveis.
} 


\section{GRÁFICO 2 DIAGRAMA DE DISPERSÃO ENTRE RECEITAS DE CAMPANHA E VOTOS NAS ELEIÇÕES DE 2012}

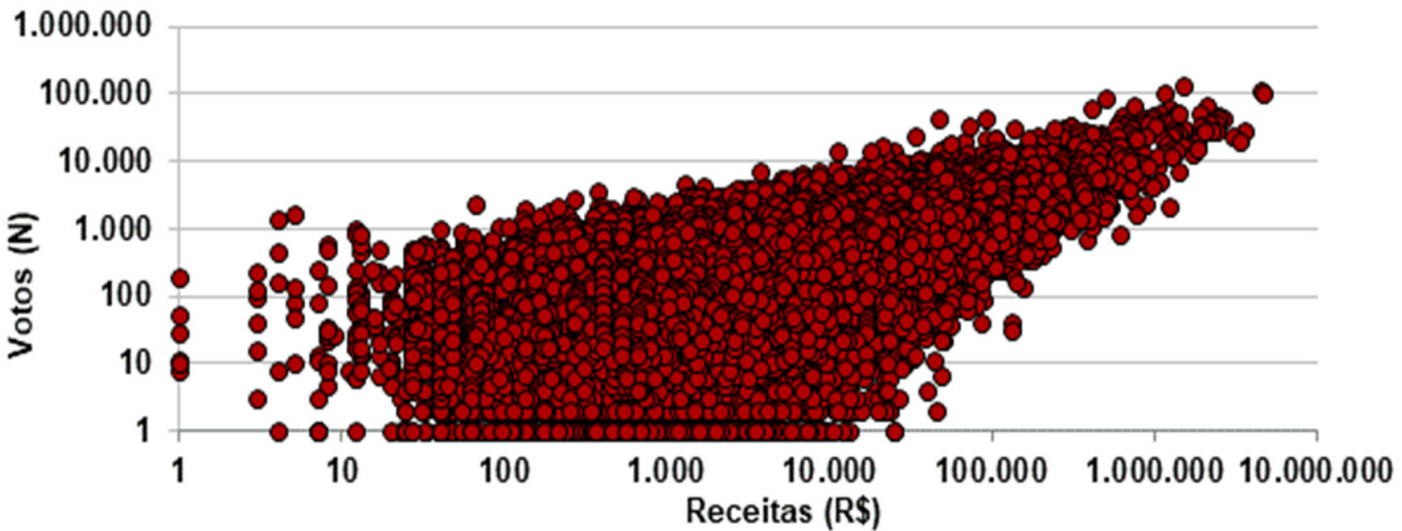

Fonte: Elaborado pelos autores com base em dados do Gete, da UEPG.

\section{GRÁFICO 3 DIAGRAMA DE DISPERSÃO ENTRE RECEITAS DE CAMPANHA E VOTOS NAS ELEIÇÕES DE 2016}

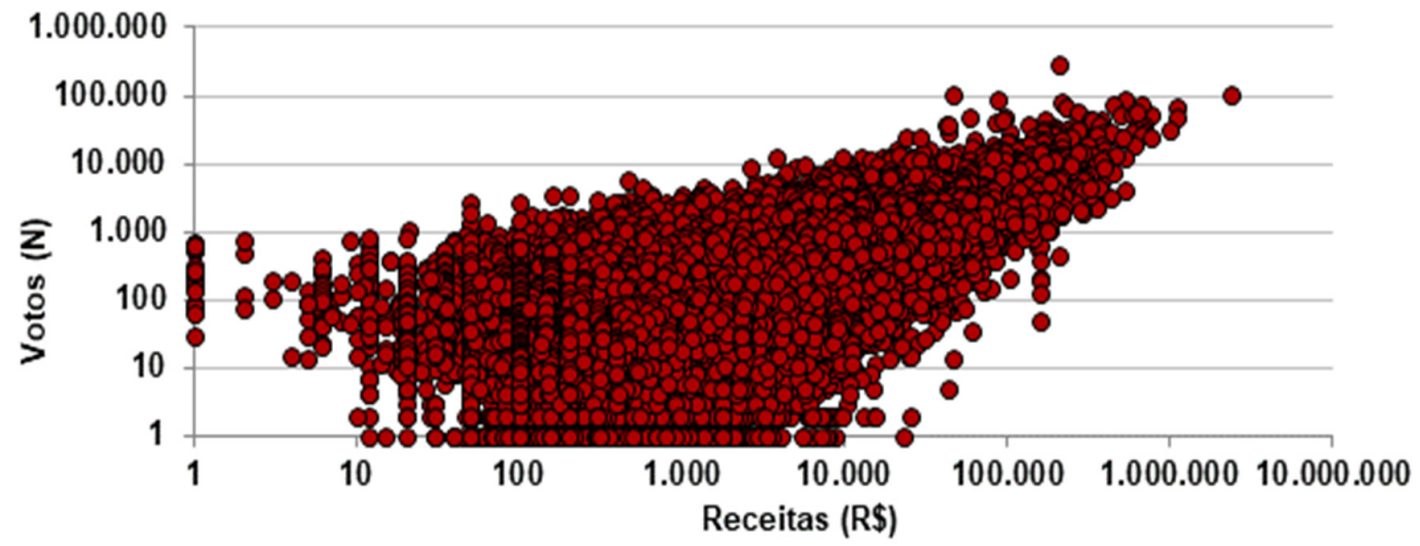

Fonte: Elaborado pelos autores com base em dados do Gete, da UEPG.

Verificada a distribuição dos dados, efetuamos os testes de correlação e regressão linear. A Tabela 2 traz os principais resultados, especificamente o coeficiente de correlação de Pearson (r), o coeficiente de determinação $\left(\mathrm{r}^{2}\right)$ e o valor-P $(\mathrm{p})$. 


\begin{tabular}{cccc}
\hline Ano & $r$ & $r^{2}$ & $p$ \\
\hline 2008 & 0,7416 & 0,5500 & $<0,0001^{2}$ \\
2012 & 0,7312 & 0,5347 & $<0,0001$ \\
2016 & 0,6192 & 0,3835 & $<0,0001$ \\
\hline
\end{tabular}

Fonte: Elaborada pelos autores com base em dados do Gete, da UEPG.

As três eleições registram forte correlação entre receitas de campanha e votos obtidos. ${ }^{3}$ Todavia, para as eleições de 2016, é necessário considerar que um candidato em específico, Eduardo Suplicy, de São Paulo, obteve 301.446 votos com uma receita total de R $\$ 207.190$, enquanto o segundo colocado obteve 107.957 votos com uma receita de $\mathrm{R} \$ 2.396 .056$. Para verificar sua influência na correlação, realizamos um ensaio, excluindo esse candidato e obtendo um coeficiente de correlação mais elevado: $0,7073\left(\mathrm{r}^{2}=0,5003\right.$ e $\left.\mathrm{p}<0,0001\right)$.

A direção e a força da correlação nos permitem buscar as equações das retas de regressão que melhor descrevem a relação entre as variáveis (Gráfico 4).

\section{GRÁFICO 4 RETAS DE REGRESSÃO LINEAR ENTRE RECEITAS DE CAMPANHA E VOTOS NAS ELEIÇÕES DE 2008, 2012 E 2016}

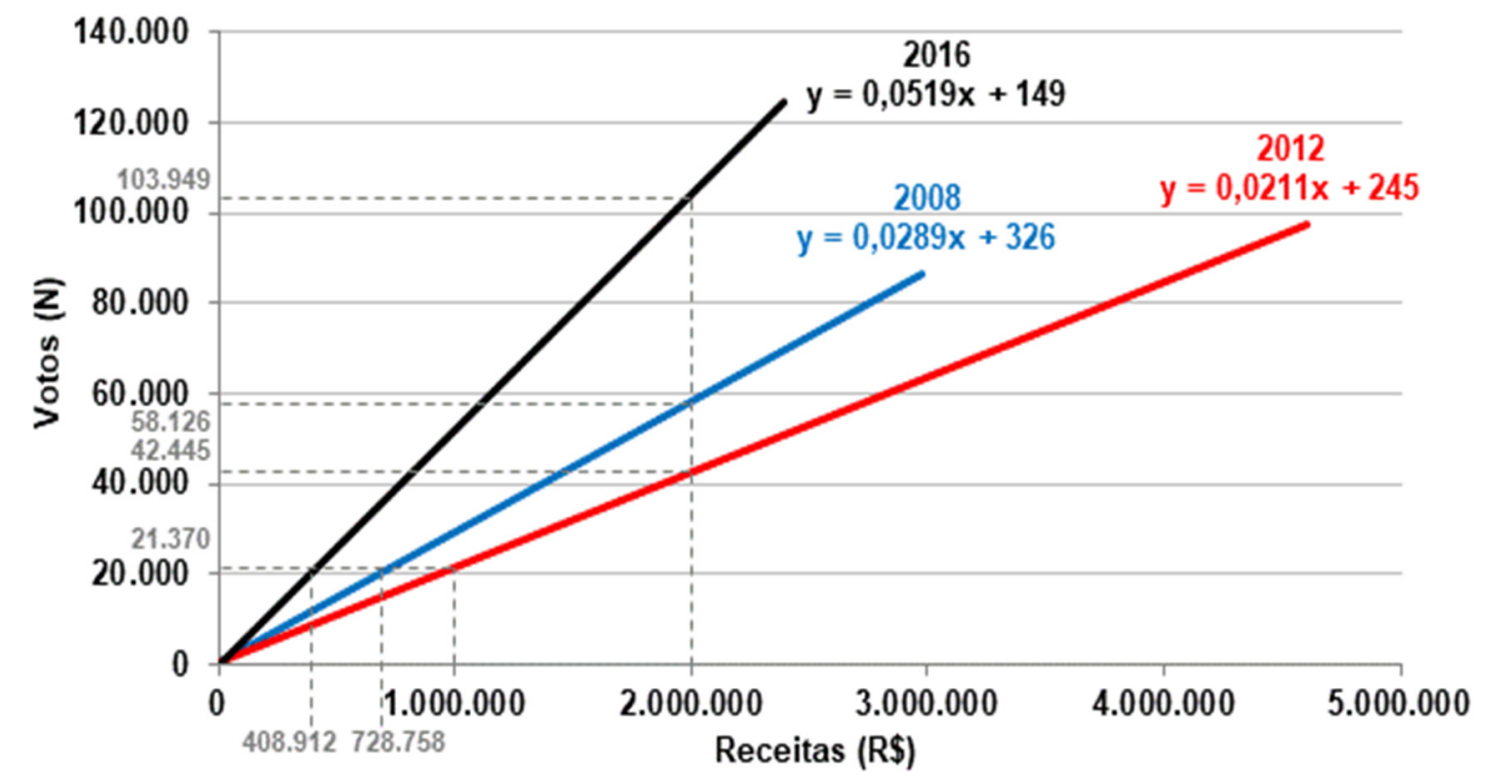

Fonte: Elaborado pelos autores com base em dados do Gete, da UEPG.

\footnotetext{
${ }^{2}$ Como $\mathrm{p}<0,05$, existem evidências estatísticas de que as variáveis estão relacionadas.

${ }^{3}$ Se $0,00<r<0,30$, a correlação pode ser considerada fraca; se $0,30 \leq r<0,60$, a correlação pode ser considerada moderada; se $0,60 \leq r<0,90$, a correlação pode ser considerada forte; se $0,90 \leq \mathrm{r}<1,00$, a correlação pode ser considerada muito forte (Callegari-Jacques, 2003). Para efeito de análises e comparações no artigo, será utilizada essa classificação.
} 
O modelo mostra que, sem recursos, o número de votos é menor a cada eleição. A equação de 2008 indica que o candidato sem receitas obteria cerca de 326 votos - intercepto dos eixos ou valor de "a" na equação de regressão. Seriam apenas 245 votos em 2012. Esse número cai em 2016, e o candidato receberia só 149 votos se nada arrecadasse.

Adicionando mil reais em receitas eleitorais - em condição de equidade, um valor relativamente plausível para a maioria dos candidatos -, temos como resultado 355 votos em 2008, 266 em 2012 e 201 em 2016. Com 10 mil reais, valor bem menos equânime, seriam 615 votos em 2008, 456 em 2012 e 668 em 2016. Acrescentando 100 mil reais, cifra nada equânime, os resultados são 3.216 votos em 2008, 2.355 em 2012 e 5.339 em 2016. Ou seja, segundo o modelo, em 2016, quanto mais díspares as condições de investimento eleitoral, mais favorecida a lógica plutocrática. O Gráfico 4 ilustra, com outros exemplos, a predição do número de votos para outros valores.

Projetamos também quantos votos são gerados por quantia de dinheiro. Adotamos a marca de mil votos, "sonho" de qualquer candidato em municípios com mais de 50 mil eleitores. O modelo permite estimar que, em 2008, eram necessários R \$ 23.321 para "produzir" mil votos; em 2012, $\mathrm{R} \$ 35.781$; e, em 2016, apenas $\mathrm{R} \$ 16.396$. Um analista pouco atento poderia comemorar a redução dos custos em 2016. Inegavelmente o voto em 2016 foi "mais barato", todavia também é verdade, pelos dados já apresentados, que o mais barato foi adquirido, em maior volume, pelos que tinham mais dinheiro. Em síntese, a influência do dinheiro sobre o voto se manteve no ciclo analisado, crescendo em 2016, quando ficou mais barato influenciar os resultados.

Procurando visualizar mais detalhadamente a correlação entre receitas e quantidade de votos, calculamos o coeficiente de correlação por município. Nas 441 cidades pesquisadas, observamos que apenas 1 em 2008 e também 1 em 2012 apresentam correlação fraca. Em 2008, 318 municípios (72,1\%) têm forte correlação. Em 2012, são 343 (77,8\%), e, em 2016, 371 (84,1\%). De maneira coerente com os dados anteriores, podemos afirmar que a força da correlação entre dinheiro e voto nas 3 eleições cresce consideravelmente nos municípios estudados.

\subsubsection{Dados relativos}

Considerando a magnitude dos distritos eleitorais analisados, correlacionamos o PCRM e o PCVM. A Tabela 3 apresenta os principais resultados.

TABELA 3 COEFICIENTES DE CORRELAÇÃO ENTRE PCRM E PCVM, POR ELEIÇÃO

\begin{tabular}{cccc} 
Ano & $r$ & $r^{2}$ & $p$ \\
2008 & 0,6766 & 0,4578 & $<0,0001$ \\
2012 & 0,6661 & 0,4437 & $<0,0001$ \\
2016 & 0,6978 & 0,4869 & $<0,0001$ \\
\hline
\end{tabular}

Fonte: Elaborada pelos autores com base em dados do Gete, da UEPG. 
Comparando aos valores de $\mathrm{r}$ da Tabela 2 - correlação entre os dados absolutos de receitas e votos -, confirma-se uma correlação forte e positiva entre as variáveis analisadas nos 3 pleitos, com equações de reta semelhantes.

A título de ensaio, como os dados relativos permitiram elaborar um ranking de arrecadação e de votação em cada distrito eleitoral, agrupamos os candidatos em quartis de participação no total de receitas do município e de participação no total de votos do município. Procedimento semelhante foi realizado por Sacchet e Speck (2012b), que reuniram os candidatos em quintis de sucesso de receitas e de votos. Na Tabela 4 , as duas participações são combinadas, formando 16 subgrupos por ano.

\section{TABELA 4 PROPORÇÃO DE CANDIDATOS (POR QUARTIS) EM FUNÇÃO DA COMBINAÇÃO ENTRE PCRM E PCVM, POR ELEIÇÃO}

\begin{tabular}{|c|c|c|c|c|c|c|c|c|}
\hline \multirow{2}{*}{\multicolumn{4}{|c|}{ Proporção de candidatos em cada subgrupo/quartil* (\%) }} & \multicolumn{5}{|c|}{ Participação do candidato no total de votos do município } \\
\hline & & & & \multirow{2}{*}{$\begin{array}{c}4 \\
17,30\end{array}$} & \multirow{2}{*}{$\begin{array}{c}3 \\
5,76\end{array}$} & \multirow{2}{*}{$\begin{array}{c}2 \\
1,64\end{array}$} & \multirow{2}{*}{$\begin{array}{c}1 \\
0,29\end{array}$} & \multirow{2}{*}{$\begin{array}{l}\text { Total } \\
25,00\end{array}$} \\
\hline \multirow{15}{*}{ A } & \multirow{6}{*}{2008} & \multirow{5}{*}{$\begin{array}{l}\text { Participação do } \\
\text { candidato no total de } \\
\text { receitas do município }\end{array}$} & 4 & & & & & \\
\hline & & & 3 & 5,19 & 9,90 & 7,40 & 2,51 & 25,00 \\
\hline & & & 2 & 1,19 & 5,42 & 9,53 & 8,86 & 25,00 \\
\hline & & & 1 & 1,32 & 3,92 & 6,43 & 3,33 & 25,00 \\
\hline & & & Total & 25,00 & 25,00 & 25,00 & 25,00 & 100,00 \\
\hline & & \multirow{5}{*}{$\begin{array}{l}\text { Participação do } \\
\text { candidato no total de } \\
\text { receitas do município }\end{array}$} & 4 & 17,32 & 5,60 & 1,74 & 0,33 & 25,00 \\
\hline & \multirow{4}{*}{2012} & & 3 & 5,23 & 9,82 & 7,38 & 2,57 & 25,00 \\
\hline & & & 2 & 1,43 & 6,18 & 9,75 & 7,64 & 25,00 \\
\hline & & & 1 & 1,02 & 3,40 & 6,12 & 4,46 & 25,00 \\
\hline & & & Total & 25,00 & 25,00 & 25,00 & 25,00 & 100,00 \\
\hline & \multirow{5}{*}{2016} & \multirow{5}{*}{$\begin{array}{l}\text { Participação do } \\
\text { candidato no total de } \\
\text { receitas do município }\end{array}$} & 4 & 17,32 & 5,33 & 1,82 & 0,53 & 25,00 \\
\hline & & & 3 & 5,18 & 9,60 & 7,07 & 3,14 & 25,00 \\
\hline & & & 2 & 1,62 & 6,60 & 9,18 & 7,60 & 25,00 \\
\hline & & & 1 & 0,88 & 3,48 & 6,92 & 3,72 & 25,00 \\
\hline & & & Total & 25,00 & 25,00 & 25,00 & 25,00 & 100,00 \\
\hline
\end{tabular}

* O subgrupo/quartil 4 é o quartil superior, ou seja, o que reúne candidatos de maior arrecadação ou de votos; o subgrupo/quartil 1 é o inferior.

Fonte: Elaborada pelos autores com base em dados do Gete, da UEPG. 
A concentração dos subgrupos com as maiores proporções de candidatos na linha diagonal, destacada em cinza, mostra a relação entre aumento da receita e do número de votos, "mais uma evidência da importância do recurso para o desempenho eleitoral", como apontado em estudo de Sacchet e Speck (2012b, p. 191).

Com os dados de participação, calculamos também o coeficiente de correlação de Pearson por município. Nos 441 municípios estudados, apenas 1 em 2008 e 1 em 2012 têm correlações fracas. Mais de 70\% dos municípios ostentam correlações fortes. Em 2008, essa intensidade de correlação esteve presente em 318 municípios (72,1\%). Em 2012, foram 343 (77,8\%), e, em 2016, $371(84,1 \%)$, maior quantidade dos 3 pleitos. Embora com algumas variações, os resultados encontrados na seção anterior e nesta são muito próximos. Ou seja, considerando ou não a magnitude dos distritos, os coeficientes quase sempre indicam forte correlação entre receitas e votos.

Nesta primeira parte dos resultados, procuramos verificar se maiores receitas de campanha resultam na obtenção de mais votos. Nas 3 eleições para o cargo de vereador pesquisadas, a correlação é estatisticamente forte e positiva entre as variáveis analisadas. Corroborando, portanto, a literatura sobre financiamento eleitoral, respondemos à questão, mostrando que dinheiro faz muita diferença na conquista de sufrágios nas eleições municipais brasileiras, sendo, inclusive, ampliada em 2016.

\subsection{A Relação entre Receita e Sucesso Eleitoral}

Procuramos identificar e analisar a relação entre receitas de campanha e resultados eleitorais, inquirindo se os candidatos eleitos recebem mais dinheiro que os não eleitos, aferindo, portanto, se mais recursos incrementam as chances de sucesso eleitoral. Realizamos as análises de 2 formas: a primeira com dados absolutos, investigando as diferenças de arrecadação entre eleitos e não eleitos; a segunda, com dados relativos, de participação do candidato no total de receitas dos candidatos no distrito/município (PCRM), objetivando verificar, além dos posicionamentos de eleitos e não eleitos por quartis de receitas, as razões de chances de sucesso em função desses posicionamentos.

\subsubsection{Dados absolutos}

Trabalhamos aqui com as diferenças entre os montantes de recursos recebidos pelos candidatos eleitos e não eleitos, calculando e comparando as receitas médias de cada um dos grupos. Começamos pela análise geral das 3 eleições, cujo resultado está na Tabela 5 . 
TABELA 5 CANDIDATOS, RECEITAS DE CAMPANHA E RECEITA MÉDIA, POR ELEIÇÃO E SITUAÇÃO (ELEITOS E NÃO ELEITOS)

\begin{tabular}{|c|c|c|c|c|c|c|c|}
\hline \multirow{2}{*}{ Ano } & \multirow{2}{*}{ Situação } & \multicolumn{2}{|c|}{ Candidatos } & \multicolumn{2}{|c|}{ Receitas de campanha } & \multirow{2}{*}{$\begin{array}{c}\text { Receita } \\
\text { média } \\
\text { R\$ }\end{array}$} & \multirow{2}{*}{$\begin{array}{c}\text { Diferença eleitos/ } \\
\text { não eleitos } \\
\%\end{array}$} \\
\hline & & $\mathrm{N}$ & $\%$ & $\mathrm{R} \$$ & $\%$ & & \\
\hline \multirow{3}{*}{2008} & Eleitos & 5.668 & 7,1 & 312.962 .705 & 35,9 & 55.216 & \multirow{3}{*}{629,1} \\
\hline & Não Eleitos & 73.752 & 92,9 & 558.537 .933 & 64,1 & 7.573 & \\
\hline & Total & 79.420 & 00,0 & 871.500 .638 & 100,0 & 0.973 & \\
\hline \multirow{3}{*}{2012} & Eleitos & 7.424 & 6,5 & 454.260 .714 & 35,5 & 61.188 & \multirow{3}{*}{685,1} \\
\hline & Não Eleitos & 106.064 & 93,5 & 826.685 .666 & 64,5 & 7.794 & \\
\hline & Total & 113.488 & 00,0 & 1.280 .946 .380 & 100,0 & 1.287 & \\
\hline \multirow{3}{*}{2016} & Eleitos & 7.565 & 6,1 & 236.466 .776 & 33,1 & 31.258 & \multirow{3}{*}{664,1} \\
\hline & Não Eleitos & 116.634 & 93,9 & 477.143 .322 & 66,9 & 4.091 & \\
\hline & Total & 124.199 & 00,0 & 713.610 .098 & 100,0 & 5.746 & \\
\hline
\end{tabular}

Fonte: Elaborada pelos autores com base em dados do Gete, da UEPG.

Nas eleições de 2008, 2012 e 2016, os vereadores eleitos correspondem a, respectivamente, 7,1\%, $6,5 \%$ e $6,1 \%$ dos candidatos, mas concentram $35,9 \%, 35,5 \%$ e 33,1\% da arrecadação. Ou seja, a receita média por eleito é muito superior à de um não eleito, com discrepâncias superiores a $600 \%$ nos três anos, chegando a $685 \%$ em 2012.

Apenas 2 municípios em 2008, 3 em 2012 e 5 em 2016 registraram diferenças entre 0\% e 100\%. Os municípios com diferenças superiores a 1.000\% foram 36 em 2008, 60 em 2012 e 45 em 2016. A maior disparidade foi na cidade do Rio de Janeiro em 2012, quando a receita média dos eleitos superou à de não eleitos em $2.517 \%$. Nos demais municípios, as diferenças ficam entre $101 \%$ e $1.000 \%$.

Em suma, a receita média dos eleitos é sempre superior à dos não eleitos em todas as cidades e em todas as eleições. Em aproximadamente $99 \%$ dos 441 municípios analisados, em média, cada vereador eleito contou com, pelo menos, o dobro dos recursos dos candidatos derrotados. São flagrantes, portanto, a influência do dinheiro para o sucesso nas eleições para vereador e as condições muito assimétricas de participação no processo democrático.

\subsubsection{Dados relativos}

Utilizamos os dados relativos da participação dos candidatos eleitos e não eleitos no total de receitas no distrito/município (PCRM) para investigar seus posicionamentos no ranking de arrecadação, classificamos eleitos e não eleitos por quartis de receitas e calculamos as razões de chances de vitória (RC) em função dessa classificação. A Tabela 6 traz os resultados. 


\section{TABELA 6 CLASSIFICAÇÃO EM QUARTIS DOS CANDIDATOS ELEITOS E NÃO ELEITOS EM FUNÇÃO DO PCRM E RAZÃO DE CHANCES, POR ELEIÇÃO}

\begin{tabular}{|c|c|c|c|c|c|c|c|}
\hline \multirow{2}{*}{ Ano } & \multirow{2}{*}{ Quartis* } & \multicolumn{2}{|c|}{ Eleitos } & \multicolumn{2}{|c|}{ Não eleitos } & \multirow{2}{*}{\multicolumn{2}{|c|}{$\mathrm{RC}-1^{\circ}$ e $4^{\circ}$ Quartil }} \\
\hline & & $\mathrm{N}$ & $\%$ & $\mathrm{~N}$ & $\%$ & & \\
\hline \multirow{5}{*}{2008} & 4 & 5.064 & 89,3 & 14.791 & 20,1 & \multirow{5}{*}{251,4} & \multirow{5}{*}{$\begin{array}{l}\text { Candidatos do } 4^{\circ} \text { quarti } \\
\text { têm } 251,4 \text { vezes mais } \\
\text { chances de serem } \\
\text { eleitos. }\end{array}$} \\
\hline & 3 & 509 & 9,0 & 19.346 & 26,2 & & \\
\hline & 2 & 68 & 1,2 & 19.787 & 26,8 & & \\
\hline & 1 & 27 & 0,5 & 19.828 & 26,9 & & \\
\hline & Total & 5.668 & 100,0 & 73.752 & 100,0 & & \\
\hline \multirow{5}{*}{2012} & 4 & 6.806 & 91,7 & 21.566 & 20,3 & & \multirow{5}{*}{$\begin{array}{l}\text { Candidatos do } 4^{\circ} \text { quartil } \\
\text { têm } 470,9 \text { vezes mais } \\
\text { chances de serem } \\
\text { eleitos. }\end{array}$} \\
\hline & 3 & 517 & 7,0 & 27.855 & 26,3 & & \\
\hline & 2 & 82 & 1,1 & 28.290 & 26,7 & 470,9 & \\
\hline & 1 & 19 & 0,3 & 28.353 & 26,7 & & \\
\hline & Total & 7.424 & 100,0 & 106.064 & 100,0 & & \\
\hline \multirow{5}{*}{2016} & 4 & 6.998 & 92,5 & 24.051 & 20,6 & \multirow{5}{*}{29,9} & \multirow{5}{*}{$\begin{array}{l}\text { Candidatos do } 4^{\circ} \text { quartil } \\
\text { têm } 429,9 \text { vezes mais } \\
\text { chances de serem } \\
\text { eleitos. }\end{array}$} \\
\hline & 3 & 481 & 6,4 & 30.569 & 26,2 & & \\
\hline & 2 & 65 & 0,9 & 30.985 & 26,6 & & \\
\hline & 1 & 21 & 0,3 & 31.029 & 26,6 & & \\
\hline & Total & 7.565 & 100,0 & 116.634 & 100,0 & & \\
\hline
\end{tabular}

* O subgrupo/quartil 4 é o quartil superior, ou seja, o que reúne candidatos de maior arrecadação; o subgrupo/quartil 1 é o inferior. Fonte: Elaborada pelos autores com base em dados do Gete, da UEPG.

Em todas as eleições, a grande maioria dos vereadores eleitos está no quartil superior, que concentra os $25 \%$ de candidatos que mais arrecadaram. Em 2008, 89,3\% dos eleitos estavam nesse quartil. Em 2012, eram $91,7 \%$, e, em 2016, 92,5\%. No quartil inferior, há poucos vitoriosos: apenas 0,5\% em 2008 e $0,3 \%$ em 2012 e 2016. Comparando eleitos e não eleitos dos quartis superior e inferior, aqueles levam enorme vantagem. Estar no quartil superior, ou seja, arrecadar mais, aumentou em 251 vezes as chances de êxito em 2008, 471 vezes em 2012 e 430 vezes em 2016.

Em 124 municípios em 2008, 133 em 2012 e 135 em 2016, todos os eleitos compuseram o quartil superior, o qual reuniu mais de $80 \%$ dos eleitos na maioria dos municípios - 322 em 2008, 354 em 2012 e 370 em 2016. Em apenas 3 municípios, em 2008 e 2016, os eleitos do quartil superior não passaram de $50 \%$ do total. Nos demais 438 (em 2012 foram todos), pelo menos $51 \%$ dos eleitos pertenciam ao quartil de maior arrecadação. Não foi nem possível calcular as razões de chances em 93\% dos municípios em 2008 e 2016, e em $94 \%$ em 2012, porque nenhum 
dos eleitos fazia parte do quartil inferior de receita. Ou seja, em 93\% dos municípios analisados, um candidato a vereador que estivesse entre os $25 \%$ com menor arrecadação teria chance zero de ser eleito.

Tanto os dados absolutos quanto os relativos apresentados aqui convergem com a literatura, e, utilizando as palavras de Sacchet e Speck (2012b, p. 183), "podemos concluir que o financiamento das campanhas tem uma estreita relação com o sucesso eleitoral”.

\section{CONSIDERAÇÕES FINAIS}

Os resultados desta pesquisa confirmam amplamente nossa hipótese de que nem a proibição do financiamento empresarial de campanhas, a partir das eleições de 2016, foi capaz de alterar o padrão vigente nas eleições municipais anteriores de forte relação entre recursos financeiros, desempenho e sucesso eleitoral dos candidatos a vereador nos municípios pesquisados.

As correlações e as regressões mostram que, no último pleito, a associação entre dinheiro e voto foi mais íntima do que em 2008 e 2012, de modo que a iniquidade entre candidatos ficou maior. As análises de receita média, classificação por quartis e razão de chances apontam que, para ampliar as possibilidades de êxito nas eleições, é fundamental se posicionar entre os campeões de financiamento eleitoral. Em 93\% dos municípios brasileiros, nenhum dos eleitos fazia parte do quartil de menor arrecadação.

A manutenção de um padrão temporal e geográfico sugere a existência de características mais ou menos estruturais no financiamento dos candidatos a vereador nos municípios pesquisados, em linha com as pesquisas sobre outros cargos. Concluímos que os impactos mais claros do dinheiro nas eleições são um desequilíbrio na competição entre os candidatos e o estabelecimento de uma dinâmica plutocrática que corrompe a democracia no país. Esses impactos em nada foram afetados pelo fim do financiamento empresarial.

Tal quadro reforça a necessidade, relatada por diversos autores, de ampliar os estudos sobre a dinâmica plutocrática e suas consequências para o regime democrático no Brasil. Uma das possibilidades nesse sentido é pesquisar o perfil dos doadores que assomaram como financiadores centrais na ausência das empresas. Candidatos ricos financiando as próprias campanhas? A elite de proprietários das empresas e do capital? Caciques partidários decidindo a destinação dos crescentes recursos públicos? São hipóteses a serem testadas. 


\section{REFERÊNCIAS}

Araújo, G. B. (2012). Contribuições de campanha influenciam decisões públicas? O caso dos contratos públicos federais e das emendas ao orçamento no Brasil (Tese de Doutorado). Universidade de São Paulo, São Paulo, SP.

Arvate, P. R., Barbosa, K., \& Fuzitani, E. (2013). Campaign donation and government contracts in Brazilian states (Working Paper n. 336). São Paulo, SP: Escola de Economia de São Paulo da Fundação Getulio Vargas.

Bianchi, A., \& Aliaga, L. (2011). Força e consenso como fundamentos do Estado: Pareto e Gramsci. Revista Brasileira de Ciência Política, 5, 17-36. Recuperado de https://doi.org/10.1590/S010333522011000100002

Boas, T. C., Hidalgo, F. D., \& Richardson, N. P. (2014). The spoils of victory: campaign donations and government contracts in Brazil. The Journal of Politics, 76(2), 415-429. Recuperado de https://doi. org/10.1017/S002238161300145X

Callegari-Jacques, S. M. (2003). Bioestatística: princípios e aplicações. Porto Alegre, RS: Artmed.

Carazza, B. (2018). Dinheiro, eleições e poder: as engrenagens do sistema político brasileiro. São Paulo, SP: Companhia das Letras.

Cervi, E. U. (2010). Financiamento de campanhas e desempenho eleitoral no Brasil: análise das contribuições de pessoas físicas, jurídicas e partidos políticos às eleições de 2008 nas capitais de Estado. Revista Brasileira de Ciência Política, 4, 135-167. Recuperado de https://periodicos.unb.br/index.php/ rbcp/article/view/1712/1508

Cervi, E. U., Costa, L. D., Codato, A., \& Perissinotto, R. (2015). Dinheiro, profissão e partido: a vitória na eleição para deputado federal no Brasil em 2010. Revista Sociedade e Estado, 30(1), 189-205. Recuperado de http://www.scielo. $\mathrm{br} / \mathrm{scielo}$.php? script=sci_arttext $\& \mathrm{pid}=\mathrm{S} 0102$ 69922015000100189\&lng=en\&nrm=iso

Chagas, L. S., Haddad, E. A., \& Chagas, A. L. S. (2015). Uma análise da interação entre empresas nas contribuições de campanhas para obtenção de contratos com o Governo Federal (Working Paper TD Nereus 07-2015). São Paulo, SP: Núcleo de Economia Regional e Urbana da FEA/USP.
Codato, A. (2014). Classe política e regime autoritário: os advogados do Estado Novo em São Paulo. Revista Brasileira de Ciências Sociais, 29(84), 145-163. Recuperado de https://www.scielo.br/scielo. php?pid=S0102-69092014000100010\&script $=$ sci_ arttext

Couto, C. G. (2012). Oligarquia e processos de oligarquização: o aporte de Michels à análise política contemporânea. Revista de Sociologia Política, 20(44), 47-62. Recuperado de http://www. scielo.br/scielo.php?script=sci_arttext\&pid=S0104$44782012000400004 \& \operatorname{lng}=$ en $\&$ nrm $=$ iso

Dawood, Y. (2015). Campaign Finance and American Democracy. Annual Review of Political Science, 18(1), 329-348. Recuperado de https://doi.org/10.1146/ annurev-polisci-010814-104523

Dias, B. P., Nossa, V., \& Monte-Mor, D. S. (2018). $\mathrm{O}$ investimento público influencia na reeleição? Um estudo empírico nos municípios do estado do Espírito Santo. Revista de Administração Pública, 52(5), 880-898. Recuperado de http:// bibliotecadigital.fgv.br/ojs/index.php/rap/article/ view/76973/73753

Figueiredo, D. B., Filho. (2009). O elo corporativo? Grupos de interesse, financiamento de campanha e regulação eleitoral (Dissertação de Mestrado). Universidade Federal de Pernambuco, Recife, PE.

Finer, S. E. (1968). Pareto and pluto-democracy: The retreat to Galapagos. The American Political Science Review, 62(2), 440-450. Recuperado de https://doi. org/10.2307/1952939

Geara, L. E., Junckes, I. J., Horochovski, R. R., \& Clemente, A. J. (2018). O financiamento eleitoral nas comissões permanentes da Câmara dos Deputados: uma análise do metarrelacionamento entre empresas e parlamentares. E-Legis-Revista Eletrônica do Programa de Pós-Graduação da Câmara dos Deputados, 11(26), 60-81. Recuperado de http://elegis.camara.leg.br/cefor/index.php/e-legis/article/ view/409

Heiler, J. G. (2011). Democracia: o jogo das incertezas $x$ financiamento de campanhas. Uma análise das prestações de contas das campanhas de vereadores de SC (Dissertação de Mestrado). Universidade Federal de Santa Catarina, Florianópolis, SC.

Horochovski, R. R., Junckes, I. J., \& Serafim, T. R. (2020). A quem interessam as políticas ambientais? 
Redes de financiamento eleitoral empresarial na Comissão de Meio Ambiente e Desenvolvimento Sustentável (Cmads) da Câmara dos Deputados. E-Legis-Revista Eletrônica do Programa de PósGraduação da Câmara dos Deputados, 13(31), 32-60. Recuperado de http://e-legis.camara.leg.br/cefor/ index.php/e-legis/article/view/533

Horochovski, R. R., Junckes, I. J., Silva, E. A., Silva, J. M., \& Camargo, N. F. (2016). Estruturas de poder nas redes de financiamento político nas eleições de 2010 no Brasil. Opinião Pública, 22(1), 28-55. Recuperado de http://www.scielo.br/scielo.php?script=sci_ arttext\&pid=S0104-62762016000100028

Junckes, I. J., Horochovski, R. R., Camargo, N. F., Silva, E. A., \& Chimin, A. B., Jr. (2019). Poder e democracia: uma análise da rede de financiamento eleitoral em 2014 no Brasil. Revista Brasileira de Ciências Sociais, 34(100), 1-22. Recuperado de https://doi.org/10.1590/3410006/2019

Lemos, L. B., Marcelino, D., \& Pederiva, J. H. (2010). Porque dinheiro importa: a dinâmica das contribuições eleitorais para o Congresso Nacional em 2002 e 2006. Opinião pública, 16(2), 366-393. Recuperado de http://www.scielo.br/scielo.php?script=sci_ arttext\&pid=S0104-62762010000200004

Levitsky, S., \& Ziblatt, D. (2018). Como as democracias morrem. São Paulo, SP: Zahar.

Mancuso, W. P. (2015). Investimento eleitoral no Brasil: balanço da literatura (2001-2012) e agenda de pesquisa. Revista de Sociologia e Política, 23(54), 155-183. Recuperado de http://www.scielo.br/pdf/ rsocp/v23n54/0104-4478-rsocp-23-54-0155.pdf

Mancuso, W. P., Horochovski, R. R., \& Camargo, N. F. (2018). Financiamento eleitoral empresarial direto e indireto nas eleições nacionais de 2014. Revista Brasileira de Ciência Política, 27, 9-36. Recuperado de http://www.scielo.br/pdf/rbcpol/n27/2178-4884rbcpol-27-9.pdf

Mancuso, W. P., Santos, M. L., Resende, C. A. D. S., \& Barboza, D. P. (2020). Financiamento eleitoral e comportamento parlamentar: a relação entre doações da indústria e proposição de leis (Texto para discussão, 2578). Rio de Janeiro, RJ: Instituto de Pesquisa Econômica Aplicada. Recuperado de https://www.ipea.gov.br/portal/images/stories/ PDFs/TDs/td_2578.pdf
Mancuso, W. P., \& Speck, B. W. (2014). Financiamento de campanhas e prestação de contas. Cadernos Adenauer, 15(1), 135-150. Recuperado de http:// www.kas.de/wf/doc/13776-1442-5-30.pdf

Mancuso, W. P., \& Speck, B. W. (2015). Financiamento empresarial na eleição para deputado federal (20022010): determinantes e consequências. Teoria \& Sociedade, 23(2), 103-125. Recuperado de http:// bibliotecadigital.tse.jus.br/xmlui/handle/bdtse/4566

Michels, R. (1982). Sociologia dos partidos políticos. Brasília, DF: UnB.

Miguel, L. F. (2014). Democracia e representação: territórios em disputa. São Paulo, SP: Unesp.

Milanovic, B. (2016). Global inequality: a new approach for the age of globalization. Cambridge, MA: Harvard University Press.

Mosca, G. (1939). The Ruling Class. New York, NY: McGraw Hill Book Company.

Pareto, V. (1966). As elites e o uso da força na sociedade. In A. Souza (Org.), Sociologia política. Rio de Janeiro, RJ: Zahar.

Peixoto, V. (2010). Eleições e financiamento de campanhas no Brasil (Tese de Doutorado). Instituto Universitário de Pesquisas, Rio de Janeiro, RJ.

Reis, B. P. W., \& Eduardo, F. L. (2019). A distância entre intenção e gesto: consequências da proibição de doações eleitorais por pessoas jurídicas nas eleições municipais de 2016. Boletim de Análise PolíticoInstitucional, 21, 67-76. Recuperado de https://www. ipea.gov.br/portal/images/stories/PDFs/boletim_ analise_politico/191021_bapi_21_artigo_6.pdf

Sacchet, T., \& Speck, B. W. (2012a). Dinheiro e sexo na política brasileira: financiamento de campanha e desempenho eleitoral em cargos legislativos. In: J. E. D. Alves, C. R. J. Pinto, \& F. Jordão (Orgs.), Mulheres nas eleições 2010. São Paulo, SP: ABCP/Secretaria de Políticas para as Mulheres.

Sacchet, T., \& Speck, B. W. (2012b). Financiamento eleitoral, representação política e gênero: uma análise das eleições de 2006. Opinião pública, 18(1), 177-197. Recuperado de http://www.scielo.br/scielo.php?script=sci_ arttext\&pid=S0104-62762012000100009

Sampaio, D., \& Figueiredo, D. B., Filho. (2019). Como o dinheiro influencia as eleições municipais 
no Brasil: uma revisão sistemática. Revista Brasileira de Informação Bibliográfica em Ciências Sociais, 88, 1-25. Recuperado de http://anpocs.com/images/BIB/ n88/1017666bib88052019.pdf

Samuels, D. (2001). Money, elections, and democracy in Brazil. Latin American Politics and Society, 43(2), 27-48. Recuperado de https:/doi. org/10.1111/j.1548-2456.2001.tb00398.x

Santos, B. C. (2016). Interesses econômicos, representação política e produção legislativa no Brasil sob a ótica do financiamento de campanhas eleitorais (Tese de Doutorado). Universidade Federal de Minas Gerais, Belo Horizonte, MG.

Santos, M. L., Silva, M. B., Figueiredo, D. B., Filho, \& Rocha, E. C. (2015). Financiamento de campanha e apoio parlamentar à Agenda Legislativa da Indústria na Câmara dos Deputados. Opinião Pública, 21(1), 33-59. Recuperado de https://doi.org/10.1590/1807019121133

Scarrow, S. E. (2007). Political finance in comparative perspective. Annu. Rev. Polit. Sci., 10, 193-210. Recuperado de https://www.annualreviews.org/doi/ abs/10.1146/annurev.polisci.10.080505.100115

Silva, B. F., \& Cervi, E. U. (2017). Padrões de financiamento eleitoral no Brasil: as receitas de postulantes à Câmara dos Deputados em 2010 e 2014. Revista Brasileira de Ciência Política, 23, 75-110. Recuperado de http:// www.scielo.br/scielo.php? script =s ci_ arttext\&pid=S0103-33522017000200075
Speck, B. W. (2005). Reagir a escândalos ou perseguir ideais? A regulação do financiamento político no Brasil. Cadernos Adenauer, 6(2), 123-159. Recuperado de https://www.kas.de/c/document_ library/get_file?uuid=80ada830-0761-8346-58c62 fc8deb12bb0\&groupId $=265553$

Speck, B. W. (2016). Game over: duas décadas de financiamento de campanhas com doações de empresas no Brasil. Revista de Estudios Brasileños, 3(4), 125-135. Recuperado de http://bibliotecadigital. tse.jus.br/xmlui/handle/bdtse/4404

Speck, B. W., \& Cervi, E. U. (2016). Dinheiro, tempo e memória eleitoral: os mecanismos que levam ao voto nas eleições para prefeito em 2012. Dados, 59(1), 53-90. Recuperado de http://www.scielo.br/scielo.php?script=sci_ arttext\&pid=S0011-52582016000100053

Supremo Tribunal Federal. (2011). Ação Direta de Inconstitucionalidade $n^{\circ} 4.650$ - Distrito Federal. Petição inicial. Relator: Ministro Luiz Fux. Brasília, DF: Diário da Justiça Eletrônico. Recuperado de http://redir.stf.jus.br/paginadorpub/ paginador.jsp?docTP=TP\&docID=1432694\&prcI $\mathrm{D}=4136819$ \#

Supremo Tribunal Federal. (2016). Ação Direta de Inconstitucionalidade $n^{\circ} 4.650$ - Distrito Federal. Inteiro Teor do Acórdão. Relator: Ministro Luiz Fux. Brasília, DF: Diário da Justiça Eletrônico. Recuperado de http://portal.stf.jus.br/processos/ downloadPeca.asp?id=308746530\&ext=.pdf 


\section{Jacques Paul Deschamps}

iD

https://orcid.org/0000-0001-8353-8014

Mestre em Desenvolvimento Territorial Sustentável; Técnico administrativo do Setor Litoral da Universidade Federal do Paraná (UFPR). E-mail: jacques_des@yahoo.com.br

\section{Ivan Jairo Junckes}

iD

https://orcid.org/0000-0001-8305-3754

Doutor em Sociologia Política; Professor associado do Curso de Administração Pública da Universidade Federal do Paraná (UFPR). E-mail: ivanjj@ufpr.br

\section{Rodrigo Rossi Horochovski}

iD

https://orcid.org/0000-0003-1135-0543

Doutor em Sociologia Política; Professor associado do Curso de Administração Pública da Universidade Federal do Paraná (UFPR). E-mail: rodrigoh33@gmail.com

\section{Neilor Fermino Camargo}

iD

https://orcid.org/0000-0003-2469-3537

Doutorando em Ciência Política; Professor assistente do Curso de Administração Pública da Universidade Federal do Paraná (UFPR). E-mail: camargon@gmail.com 